Supplement of Solid Earth, 10, 581-598, 2019

https://doi.org/10.5194/se-10-581-2019-supplement

(C) Author(s) 2019. This work is distributed under

the Creative Commons Attribution 4.0 License.

(c) (1)

Supplement of

\title{
The cross-dip correction as a tool to improve imaging of crooked-line seismic data: a case study from the post-glacial Burträsk fault, Sweden
}

Ruth A. Beckel and Christopher Juhlin

Correspondence to: Ruth A. Beckel (ruth.beckel@geo.uu.se)

The copyright of individual parts of the supplement might differ from the CC BY 4.0 License. 


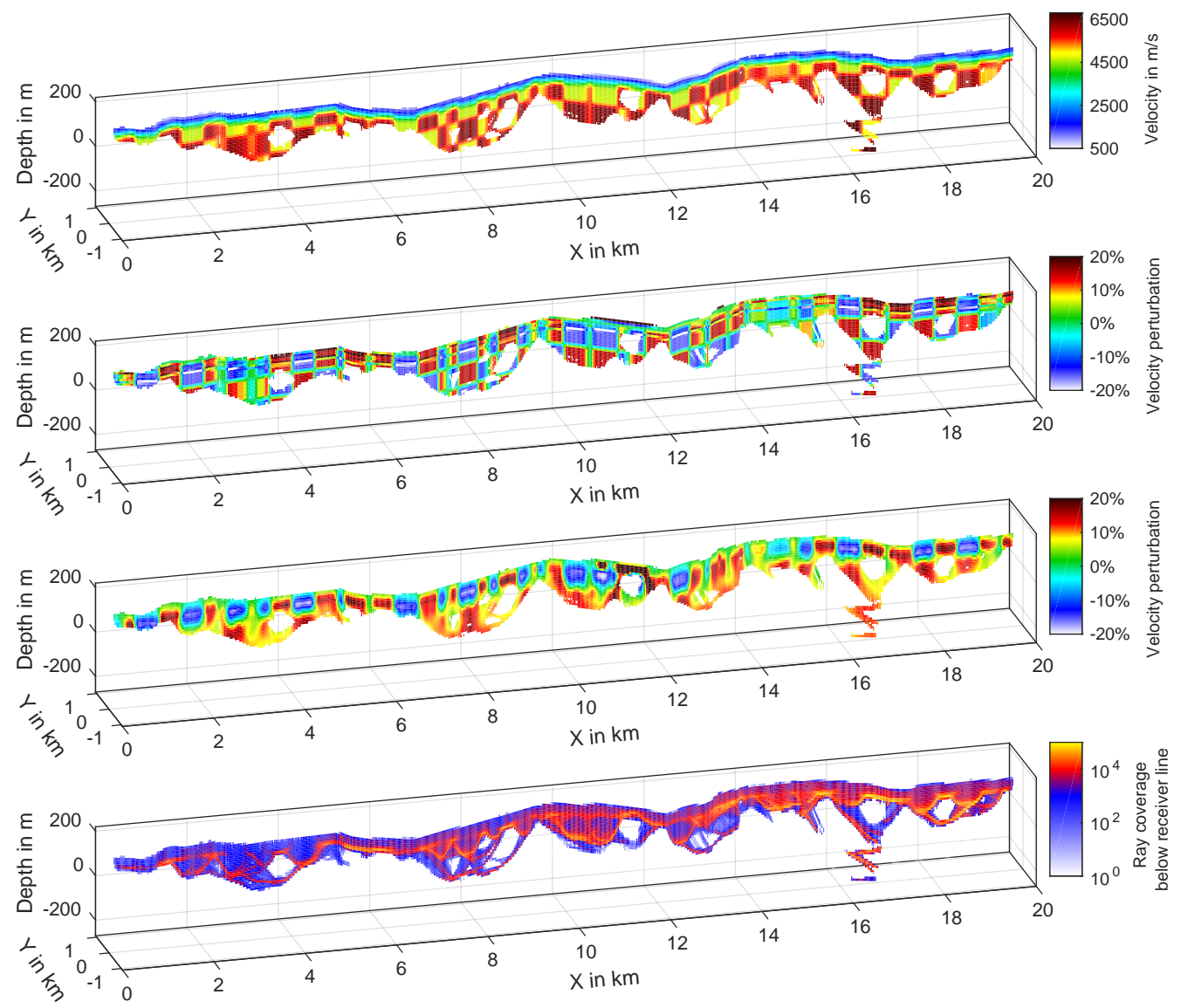

Figure S1. Checkerboard test illustrating the resolving power of the tomography. From top to bottom: velocity distribution of the checkerboard model; relative velocity perturbation of the checkerboard model; reconstruction of the checkerboard model after inversion; ray path coverage below the receiver line. Note that the checkerboard model is three-dimensional and that the sections displayed here only show the model below the receiver line. The Checkerboard test indicates that the velocities in the uppermost part of the bedrock are well resolved. In the lower parts of the model, the checkers are not well reconstructed, indicating that the velocities in this part should be interpreted with care. 